\title{
Pietilä's Crystal for the Finnish President
}

\author{
Kati Blom \\ Lecturer at Newcastle University, School of Architecture, Planning and Landscape, Claremont Tower, NE1 \\ 7RU, Newcastle-upon-Tyne, United Kingdom. \\ Telephone: 00-44-1912226003, Email: Katriina.Blom@ncl.ac.uk
}

doi:10.5618/arch.v2.1 || Received: 2012-11-26, Accepted: 2012-12-2, Available online: 2012-12-12

\begin{abstract}
This article investigates in detail the Finnish rationalist reception of so-called humane modern architecture and especially the Pietiläs proposed and then built design for the residence of the Finnish President (Mica Moraine, later Mäntyniemi in Helsinki 1983-1992). It argues that the opponents of the proposal were dismissing the architectural aim to integrate cultural and geographical context to the spatial experience, rather than imitate natural (biomorphic) or primitive (vernacular) forms. The accusations at the time were based on the premise that the forms of the proposal - Mica Moraine- were representing the past. The spatiality of Pietilä's genius loci approach is revisited by contrasting Pietilä's oeuvre to that of Mikko Heikkinen and Markku Komonen (Lume in Helsinki 2000) and the reception of the latter. Formal rational perception of romantic or organic architecture in Finland dismisses the experiential approach of Pietilä's architecture, which uses different spatial media to reach a point where architecture can no longer be judged via visual media, but only by experiencing a temporal spatial event of the play of interiority and exteriority.
\end{abstract}

The aim of this article is to give the Anglo-Saxon audience an insight of the Finnish architectural discussion in the late $20^{\text {th }}$ century. Finnish texts by Vilhelm Helander, Juhani Pallasmaa, Reima Pietilä, and Asko Salokorpi are used, and AngloSaxon references like those of Malcolm Quantrill's, and Sarah Menin's are used to investigate an external, contemporary view of Finnish architecture's most heroic period.

Keywords: Finnish architecture; Raili and Reima Pietilä architects and Mica Moraine / Mäntyniemi, Heikkinen-Komonen architects and Lume, rationalism; genius loci; spatial experience; formal criteria in criticism; accusations of primitivism.

\section{Introduction}

Over the past 50 years, the Finnish architectural discourse had been polarised between mainstream
Rationalism and what seems to be - from the view of the Rationalistic camp - an idiosyncratic Expressionism. In this debate romantic, expressionistic and organic are used as synonyms. All non-rectangular forms are summed as exceptions: crystalline or organic forms, zoo- or geomorphologic, but more importantly, not incorporating spatial experiences into this equation. This article will study this position in relation to Reima Pietilä's (1923-1993) architecture, and specifically his last work, the official residence of the President of Finland, Mica Moraine, later called Mäntyniemi, (1983-1992) .

The formal accusations by rationalists dismissed the topological site-specificities or methodical depth of his architecture, not to mention the experiential or kinaesthetic aspirations. These are all favoured by Alvar Aalto (1898-1976), Reima Pietilä and lately also by Juha Leiviskä (1936- ). ${ }^{1}$ These architects have been called, especially in Britain, Finnish alchemists of the difficult cult of compounding nature and functionalism or especially in connection with Aalto, who represents a humane approach. Most relevant is surely Colin St John Wilson in his "The Other Tradition of Modern Architecture: The Uncompleted Project". ${ }^{2}$

What looks from outside to be a humane - Finnish - version of Modernism, turns to be, when viewed by Rationalists in Finland, an aversion or isolated exception from hardcore objectivism. However, without being able to completely dismiss Alvar Aalto's architecture because of its political and cultural impact on the international image of Finnish architecture, the architecture of "the other tradition" had been used as a cover image when advertising Finnish architecture abroad. ${ }^{3}$ This painful dilemma caused by being unable to fully ignore Aalto's, Pietilä's and Leiviskä's presence in the architectural arena resulted in convoluted rationalisation of the hidden repulsion felt on the powerful themes of their oeuvre. This dichotomy between the consensual architectural tradition and the other tradition has resulted in blindness of not seeing where the real difference lies; when recognising formal differences between these two traditions the critics have overlooked the spatial and experiential qualities. 

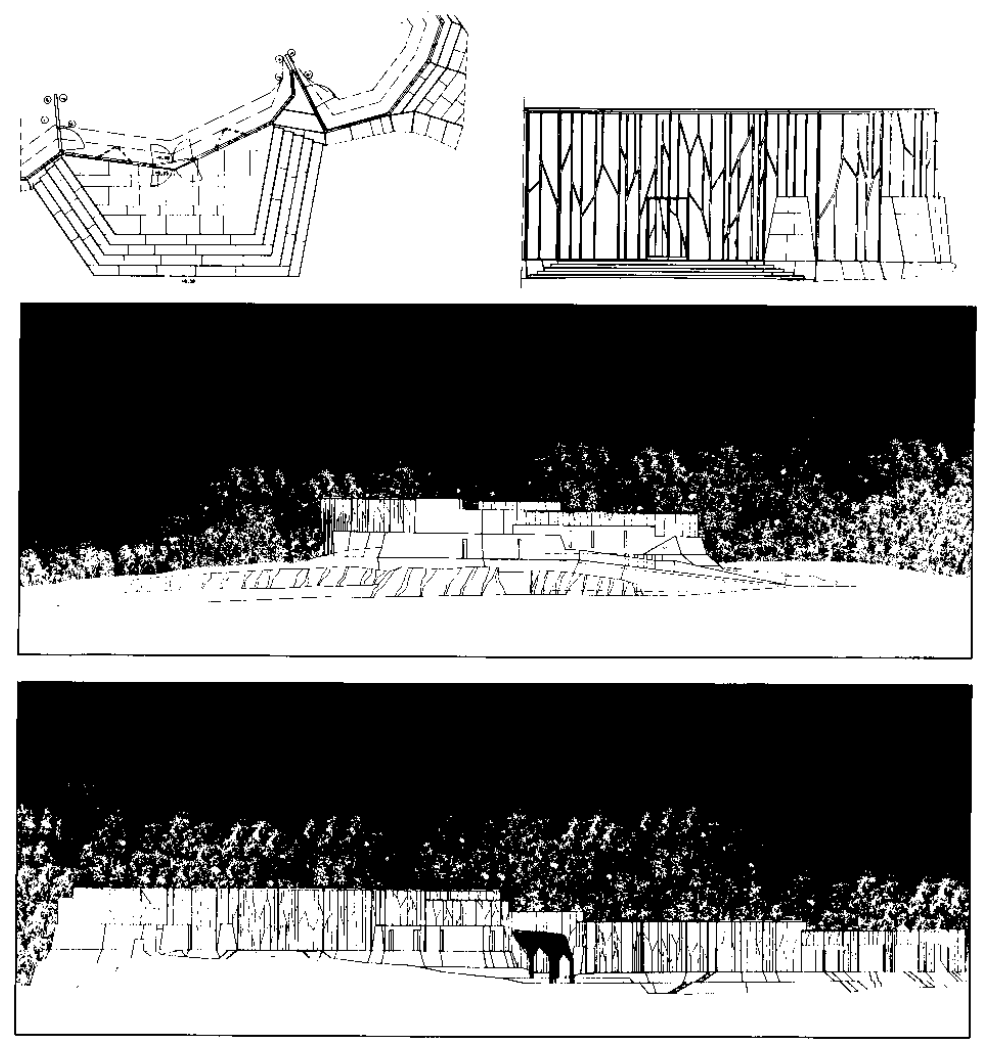

Fig. 1-4. Competition drawings for the Mica Moraine, including elevations and a sectional and plan detail of the wall.

\section{The perception of Mica Moraine}

When Reima and his wife and partner Raili Pietilä's (1926-) entry Mica Moraine ${ }^{4}$ won the competition for the president's official residence, the announcement of their success was followed by a public debate on the $24^{\text {th }}$ of May 1984 at the Museum of Finnish Architecture. ${ }^{5}$ Some of the debaters considered the winning entry a failure, having deemed it irrational. I attended this discussion, and at the time I wondered about the strong reactions, as I myself considered the solution to be very logical, organic, and site-specific. Perhaps the reactions of jealous co-competitors are understandable in the battle for a project of this importance, but obviously it was the non-Euclidean forms that triggered some of these reactions.

The Pietilä's entry uses repetition as a method in shaping the irregular composition which follows the contours smoothly. The main access was placed in the centre of the building, while the entrance court yard is a composition of two concave forms, creating two different yards: private and official. The other side of the building, facing the sea is clearly modular in its character, creating a rhythmic convex glazed façade. The overall volume is cut sharply with a flat roof, thus relating to the Pietilä's Kaleva Church (1959-1966) in Tampere, Finland. The two different façades of the building share a common angular appearance similar to mineral formations. The interiors form ever changing, vortex-like enclosures, with varying light conditions and outward views. In the exhibition catalogue of the Museum of Finnish Architecture Pietilä: Intermediate Zones in Modern Architecture (1985), the materials for Mica Moraine are summed up as follows by Pietilä: "large stone plinth varying in height with intensive use of glazed areas subdivided into a filigree branch pattern of mullions," while its architectural character is described in terms of, "Mythological forces of the Finnish nature: receding glaciation and subsequent land upheaval." 6 The formal glazier resemblances unite the interior and exterior.

The Mica Moraine project had two key precedents: the Kaleva church, already mentioned, and Dipoli, the Students' Union Building of Helsinki University of Technology in Otaniemi (1966). In the Kaleva church one finds the idea of a rock like appearance- a homogeneous monolith - which is opened up via a filigreed web of interspaces which punctuate movements of the visitor inside the church. Pietilä explains that "...in good modern architecture the exterior and interior spaces form a constructive union. Perhaps in the church, a certain 'genius loci' together with construction becomes 'metaphorical'. In other words - an architectural imagery emerges and communicates." (Pietilä 1985, 42) This intended experienced fusion of embodied spatial events of 
kineasthetic gestures has been tried out in Kaleva sketch models, and revisited in Mica Moraine, according to Pietilä. In the latter Dipoli project, Pietilä would test for the first time his genius loci idea as an archetypal interiority, the Nordic cave, a conception that returns in Mica Moraine. He describes this in opposition to the architecture of 'techno-culture': instead, this is a 'nature-architecture', whose terms are in balanced co-existence:. "[...] Dipoli", he writes, "essentially expresses this consensus and context." (Pietilä 1985, 15) Both landscaping and architecture are meant to revitalise the semi-suburban site to resemble its primary (pre-industrial) condition. From the balance between the original, undamaged condition of the site, the landscaping and the congenial architecture, particularity arises as an atmosphere. If the damaged forest around Dipoli could recover via this type of architectural practice, Pietilä argues, we could sense the nature's genius loci through its continuation, or transformation into, architecture. The collision of technology and forest is emphasised in the interior by locating natural stones in the banks of the "river" of the main corridor which divides the rectangular order from the mineral one [See the plan Fig. 8].

Both Dipoli and Mica Moraine are located in an enclosed piece of forest even if they are not in a wild forest. The context is an important reminder of Finland's past as a forest-dwelling society. The central corridor of Mica Moraine is meant to be a transition from the official quarters of the President's residence via the private quarters, to the culturally most significant part of the building- which is a sauna in the west end of the corridor. The sauna in Finland is a potent symbol, a ritualised transition from culture to nature. Ideally it is located outside a dwelling, as far as to reach the water. A sauna takes several hours to warm up and requires repeated visits to the hot room. This process has national identity-building connotations being more a ritual than a habit. In Mica, the convoluted glazier-interior is organised around the central spine of the sauna -procession. This interior imagery of an exterior ritual is culturally significant.

At the time of the competition, I was working in the Pietilä's office, and I became used to the suspicious comments of friends and colleagues regarding the odd forms that the Pietilä's had used. Most frequently they referred to Dipoli, their most famous construction and a project described by Pietilä in terms that were almost identical to Mica Moraine: "Morphological exercise into the mineral world where the granite shield on the site originating from the glacial era is simulated at the roof level. The interior-exterior is an exercise in forestal morphology where space penetrates the interior as forest continuity."7
I discussed the issue of morphology with Reima Pietilä, who said to me that he had become 'a friend with all the shapes', and furthermore 'with the emotions they are related to'. Every shape has to be equally considered a possibility in architecture, for the form was not an end, but a conclusion of a wider consideration of the cultural and topographical conditions.

2.1. Accusations of primitivism. As an aftermath of the debate Arkkitehtiuutiset - the professional newsletter by the SAFA (Professional Body of Finnish Architects) - published an article by a young architect student Pirkko Eskola. ${ }^{8}$ Reima Pietilä asked my opinion about the student's writing; he himself was confused. He had invested a lot to this competition - the Finnish president Mauno Koivisto being his school-mate. Eskola argues that the shapes the Pietilä's used definitely gave a false image of Finns as primitive men of the backwoods. Eskola stated:

In my opinion the winning entry is not only disgusting non-architecture, but also pitifully oldfashioned. Raili and Reima could have designed it already 20 years ago. In 1964, the jury could have greeted it with exactly the same words as now: Finland! Nature! Finland! What does this building reveal about our time? Didn't the era of commercial architecture, which appealed to tourists, and derived from primitive nature-mysticism, end already when Dipoli was built? [emphasis added]

Typical of this statement is to assume that there is an inevitable link between forms imitating nature and feared commercialism. Consequently, Eskola did not like the jury's comment in Helsingin Sanomat (17 May 1984) about the building being 'nature itself'. She was strongly of the opinion that this tendency to designate discrete cultural productions as "natural" is highly ideological and was abandoned elsewhere long ago, not least because of its historical role in nationalistic discourses. What I am most interested in, however, is the parallel accusation that the project was 'primitive'. Amongst the various characterisations, the epithets 'old-fashioned' and 'primitive' are the only ones that neither the Pietilä's nor the press used in relation to the entry. These specifically refer to the morphology of the entry, whose non-Euclidean forms, its non-rectangularity, Eskola perceived as impractical or un-functional.

It was Eskola's claim of non-functionality to which Pietilä himself would react most strongly against. It is an accusation that is, in a Finnish context, an insult. The Finnish architectural tradition of moderation relishes practicality. Reima Pietilä was from 1954 onwards a corresponding secretary to CIAM, the cofounder of Le Carré Bleu ${ }^{9}$ and was strongly 

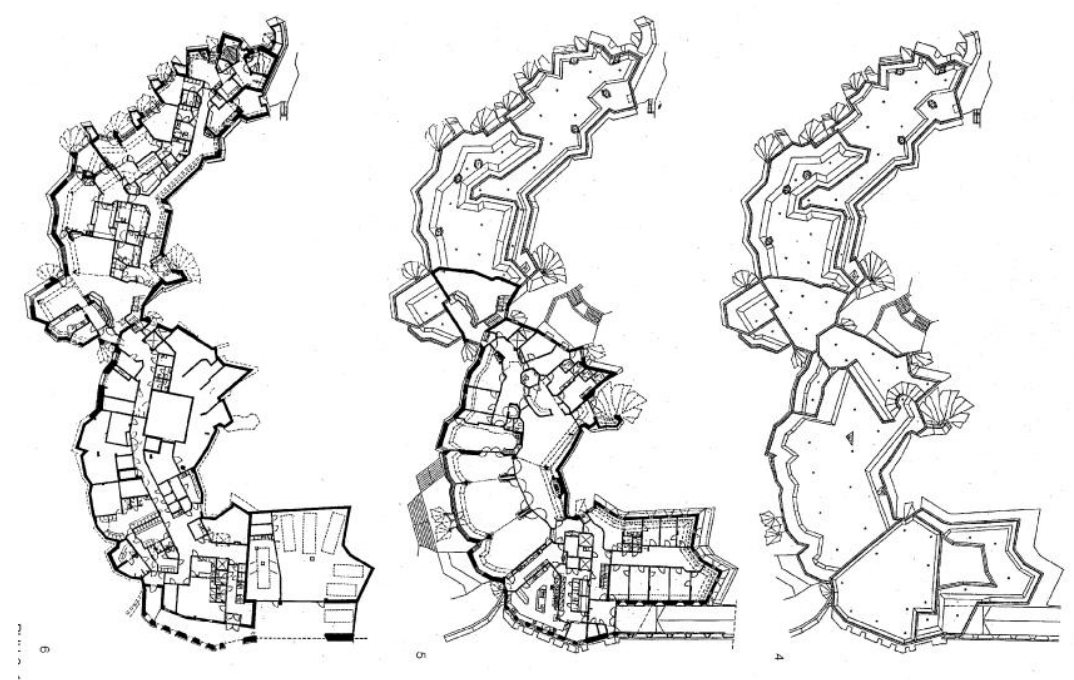

Fig. 5. Reima and Raili Pietilä's final plans for the Mica Moraine.

committed to the revigorating the ideals of modernism, and its economical, practical, technical and social aspirations unpinned his philosophy. Malcolm Quantrill even argued in 1997 that out of the three main components of Pietilä's design matrix nature, culture and function - function can be used radically in the solution thus challenging the typological assumptions. ${ }^{10}$ It is pivotal in merging all design aspects. The final form of design is not predestined to confirm any ideological, typological or formal assumptions. The only point, I argue, where he diverges from modernism is in his methodological approach to form and his tolerance of zoo- or geomorphology.

Pietilä considered the Mica Moraine to exemplify the economical central corridor type. Even if the forms are derived from nature - the mineral forms of mica - the solution is, nevertheless, purely functional. He was astonished by Eskola's implied claim about the irrationality of the design, which in this context implied 'non-functional'. Although Reima Pietilä himself had described his own architectural shapes and irregular forms as non-rational -as well as expressionistic- he made an important distinction between the non-rationality of the style (or rather the shapes used) and the functionality of topological, organisational and circulation patterns.

The philosophy is clearly stated by Pietilä when he comments on forms akin to his. In the catalogue of the exhibition held in Helsinki 1983 called How Nature Forms, texts are made jointly with US-based architect Martin Price. In the dialogue between Price and Pietilä, Price states:

The rationalists are rational only in a Euclidean geometry cause and very irrational in a cause for people. My students, in minority, choose the rational irrational, against the majority's irrational rational. ${ }^{11}$

Here Price defines an approach boarder than a method implying presupposed rectangular forms. Pietilä describes Price's architecture non-rationality by, "it is not rational." By stating it like this, he is referring it to be a deviation from the prevailing, "rational" consensus.

In another context, Pietilä declares the kinship between his entry for the Monte Carlo Multi-Purpose Building Competition (1969) and Le Corbusier's chapel of Notre-Dame-du-Haut in Ronchamp 19501954:

But the quality of the relation is hard to analyse. The chapel of Ronchamp is the most ambiguous work. The term 'ineffable-indicible' of Le Corbusier given for the poetic quality that emerged in his work in the beginning of the fifties have always intrigued me. Le Corbusier became interested in the irrational dimension implied in the tradition of architecture. He tried to unite construction with the wider context of a cultural vision [emphasis added]. (Pietilä 1985, 62).

The expressed unison between two "irrational" architectures is not formal, but based on 'affective' correspondence between cultures and shapes. This methodologically complex view seems to be dismissed in the accusations of formalism directed to Pietilä's proposal. Ultimately, this type of architecture is not to do with representation but with presence. Pietilä states, "Neither form, nor space, nor structure can be a starting point when the design method consists of a culturally oriented holistic design." (Pietilä 1985, 21) For Pietilä his architecture was functional, non-rational, and irrational, all epithets which in his philosophy referred to the recognition of wider cultural premises. 


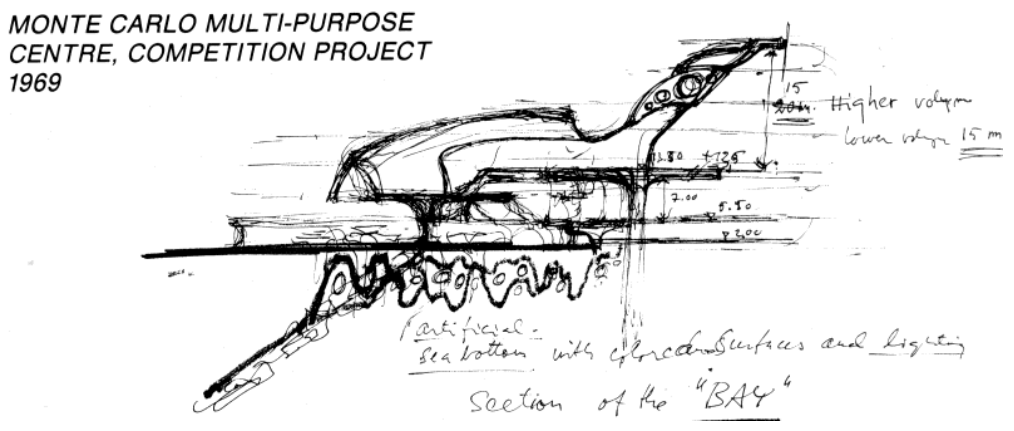

Fig. 6. Sectional sketch entry for the Monte Carlo Competition.

2.2 Binary opposition. Eskola's emotional response surely originates from the national debate, whose negative stance toward the organic is prefigured in some of the architectural writings of the previous decades, when Aalto's strong presence in the Finnish architectural scene was challenged. At this time Pietilä was seen to have formal kinship with Aalto, as noted by Alan Colquhoun:

At the end of the 1960s the conflict between these two models [rationalist and organic] came into the open. The young rationalist (or 'Constructivists', as they called themselves) opposed what they saw as the Romantic tendencies in the later work of Aalto and followers like Reima Pietilä $[\ldots]^{12}$.

These attitudes were still strong in the 80s. Juhani Pallasmaa -who belonged to the constructivists of the 60s- in his article in Swedish architectural review Arkitektur 10, 1986 singled out Aalto and the Pietilä's: in his text they represented the fusion of nationalistic, romantic and expressionistic tendencies as a "counterpoint to the Rationalist tradition." He states:

And it naturally follows [in a small country] that the leaders in arts and sciences are more likely to represent a nationalistic, romantic and expressive orientation than the opposite polarities of internationalism, rationalism or classical aesthetic ideals. $^{13}$

It is true that the main argument here about the small county's limited ideological options is valid. Anyhow, Pallasmaa's text implies inevitable dyad between romantic (nationalistic approach) and rational (internationalism) and may lead to incapacity to recognise other interpretations of the situation outside this dyad, Aalto being forced to be defined by either of these categories. As an illustration of how such oppositions structured Finnish architectural discourse we might examine Asko Salokorpi's book Suomen arkkitehtuuria 1900-luvulla (transl. The Finnish Architecture of the 20th century), published in 1971. It mirrors faithfully the beliefs of the 1960s and the 1970s. It was used as a course book in Helsinki University of Technology Department of Architecture, where Salokorpi lectured on the history of Modern architecture. The book's narrative idealises the originmyth of Finnish Modernism, using the RomanticRational dyad as an organising opposition.

The simplified dichotomy has been seen in the forefront of discussions in Finland since the turn of the $19^{\text {th }}$ and $20^{\text {th }}$ centuries, and it is referred to in Salokorpi's book. Debate circled the NationalRomantic style of the architects Herman Gezellius, Armas Lindgren and Eliel Saarinen, who ran the most prominent office of the time. They used allusions to medieval stone architecture, Karelian motifs and eclectic composition principles. The winning entry to the Main Railway station (1904-1916) was criticised by Rationalists Sigurd Fosterus and Gustav Strengell, and Salokorpi uses the epithet 'objective' for the developed and more rational scheme for the Helsinki railway station by Saarinen. ${ }^{14}$

Romantic and Expressionistic architectures were the main targets of criticism in such debates, and less frequently -, if ever, Rationalism or 'objective' forms - and this viewpoint is also evident in Salokorpi's book. ${ }^{15}$ This is partly because the Finnish NationalRomantic style, even if freed the plan of rigid symmetry of the revivalism, used vernacular motifs, materials and compositions which, from the Rationalist point of view, represented a return to the past (even if in reality National- Romantic architects considered themselves to represent the future compared to revivalism). Industrialised construction methods as such represent progress. Free form of irregular, asymmetric composition was accepted, but not the eclectic use of a large variety of motifs of vernacular or stylistic traditions, and depicted animals or plants. Pietilä by contrast uses mineral, crystalline or glazier forms and the difficulty of interpretation suddenly occurs.

Westerns architecture debate has been heavily dependent on binary oppositions up to this day. In the eve of functionalism biomorphic forms, imitations of nature and the forced spatiality of romantic architecture were criticised by Wilhelm Worringer in 
his classic thesis Abstraction and Empathy (1908). Abstraction was considered superior to ease anxieties of modern man, states Worringer, for crystalline, geomorphic or geometrical forms in art and architecture are transferred far enough from spatiality of the urban city and thus could tranquilise agoraphobia. ${ }^{16}$ If one interprets Pietilä from Worringer's point of view, he is almost as abstract and modern as Worringer can imagine, the exception being Pietilä's sense of kinaesthetic spatiality.

2.4 Plasticity. The other problematic quality associated with both the national-romantic movement and Jugend-style was a preference of plasticity of form. Plasticity is often linked with expressionistic architecture - for instance by Vittorio Gregotti in 1964- it occurred in the National-Romantic movement as well; such buildings are not 'constructivist' in the way that they would reveal the primary (frame) structure, but rather concentrate on intensifying the wall. Similarly Salokorpi argues that walls represent "regression", again reinforcing the argument against "primitivism" in Pietilä's architecture. $^{17}$

It has been noted by Gregotti that the plasticityprerequisite of Expressionism-, or strictly speaking its monumentality, was used to promote national, even nationalistic tendencies in society, especially in Germany in the years after the First World War. ${ }^{18}$ As Emily Braun has noted 1996, some Nazis supported Expressionism "as true to the mystical German spirit", even if the picture is more complicated. ${ }^{19}$ After 1933 when the National Socialists won the election, some of the best architects, both from Neues Bauen and Expressionism were criticised as degenerative and some of them eventually emigrated. Winfred Nerdinger stated (1994) that the preferred classical style maintained certain elements of either reductionism or Expressionism, mainly monumentality in public constructions and preference of the vernacular as suburban ideal. ${ }^{20}$ Expressionistic plasticity and vernacular allusions were rejected in Finland as part of the rejection of nationalism in Europe, so the formal characteristics were associated (wrongly) with Nazis. This is more problematic still knowing that similar now considered as "romantic" tendencies appeared in Scandinavia after the Second World War as a reaction to the austerity of wartime. This softness with strong links with vernacular was quickly abandoned by the rationalists of the 50s, seen as, according to Vilhelm Helander (1995), "an intermediary stage of deviation from the fundamental principles of the new architecture." ${ }^{, 1}$ In a similar tone Kirmo Mikkola suggested in the 60s that Reima Pietilä and Professor Timo Penttilä, whose architecture is more logical than intuitive, both represent "an unfortunate intermediate state in Finnish architecture".22
Thus we see a constant pendulum between the undefined 'expressionistic' and rational themes. The dilemma is not reconciled; irregularity as a guiding principle is only partially adopted - in the rule of asymmetry - causing underlying tension whenever a more conscious romantic architecture emerges. The binary opposition is repeated in 1985 in peculiarly familiar terms by Charles Jencks's Modern Movements in Architecture where Jencks sees Aalto as opposing both, "a sterile rationalism and bombastic expressionism," meaning American commercial architecture, and concludes that Aalto uses, "naturally expressive forms." (Jencks, 179, 183). For Jenck's credit, he expels Aalto from the dyad, but cannot free himself from the binary opposition.

If we would adopt a view that these tendencies are always parallel and complex, the ideological conflict would cease and ideals rather than forms would be in focus. For instance, Alvar Aalto's irregular classicism is a hybrid made possible by the freedom presented in the proceeding romantic trend, even if Aalto opposed explicitly 'romantic' motifs. This reduced, modest Scandinavian classicism of the 20 s was later easily transformed into a new Scandinavian objectivity by young Aalto. (Colquhoun, 200) On the other hand, Aalto admired the plasticity of Henry van de Velde, thus mixing eclectically motifs of different origin. (Jencks, 167)

2.5 Personal indulgence. One characteristic that was seen negative in all the "non-rational" tendencies in Finland was their close ties to the problematic figure of the romantic artist-genius. Alan Colquhoun refers to this by stating that in Finland, the $60 \mathrm{~s}$ and $70 \mathrm{~s}$ constructivists, "accused the older generation of concentrating on monumental 'cultural' buildings based on a subjectivist aesthetic lacking methodology, and of ignoring the social role of architecture." ${ }^{23}$ In recent Finnish architectural discourse, preference is given to the architect as a socially conscious servant of society, in contrast to the bogey of a hedonistic savage promoting free form. Traces of this polemical stance are seen in the way in which young Finnish architects -the Constructivists- campaigned against Aalto in the 60s. This negativity is an internal reaction to the appraisal given to genuinely 'individual approaches' of the Finnish Aalto and Pietilä.

One example of this international appraisal is Michael Dobbins who argued in the early 60s that the particular qualities normally indentified in Aalto (appropriateness, thoroughness and social responsibility) are sensed in all Finnish works, even if they are all very individual. ${ }^{24}$ Dobbins is not into the Expressionistic-Rational dyad, rather he sees the opposition of intuitive-theoretical; his view originating from what he thinks is a difference between Reima Pietilä and Aulis Blomstedt. (Dobbins, 4) The term 'individual' is used neutrally 
by Dobbins, even if the returning usage of it in Finnish context is in the ideological conflict. Vilhelm Helander also describes both Aalto and the Pietilä's as 'individuals' set deliberately in the backdrop of Scandinavian ascetism.$^{25}$

The supplementary accusation is related to the rejection of current technologies, as if quick adaptation of technical novelties would prove desired universalism. Scott Poole in his book The New Finnish Architecture states that Kristian Gullichsen's and Juhani Pallasmaa's construction system in the 1960s, Moduli 225, was their response to the expressionist, 'personal' architecture of Aalto and Pietilä:” In a sense the idea of anonymous serial production in Gullichsen's and Pallasmaa's design was a direct criticism of the personal indulgence that characterised expressionist tendencies in Finnish architecture [emphasis added]. ${ }^{26}$

The consensus of the emergence of modernism through a battle against romantic ideas of creatorgenius is thereby reinforced in the description of the 60s by both Colquhoun and Poole. Helander agrees: "Pietilä's designs are surprisingly and powerfully individual." (Helander, 28) Helander states that also Juha Leiviskä is one of the 'individuals': “The design principles of Juha Leiviskä, which utilise dynamic spatial planning and the use of light, are richly personal and immediately recognisable." (Helander, 29) These remarks are not pejorative, rather they summarise the exceptional quality of their designs. In any case, they are symptomatic in their exclusive treatment of these architects' work for there are no further comparative comments of the individualism.

In relation to the Pietilä's, this accusation of selfindulgency can be inverted, individual is not the architect's ouvre but about how Pietilä emphasises the individual singularity of the site. He sees himself first of all not as a singular creator, he sees himself as part of the so called "natural school, Ultima Thule [to the Romans], the northernmost part of Europe and seekers of its original tradition." (Pietilä 1985, 25) The role of an architect is that of an interpreter of the cultural and topographical contexts. The generalised perception of urban, functions and technology is shaped in the particularities of the quality of space, semantics and scale, as Quantrill notes (Quantrill, 129). His method is less concerned about the final object, and more concerned about space in relation to its environment, to the grade of the shape becoming oddly distinctive. In the urban context, states Quantrill, the architecture aligns with protective symbolic cultural expectations (outside in); in virgin wooded areas - like Mäntyniemi - the architecture applies non-Euclidian forms to emphasise the interconnectedness with environs (inside out). In brief, this method recognises the need for a contingent adaptation of cultural conventions, where the individual site is the point of departure, not the interpreter him/herself.

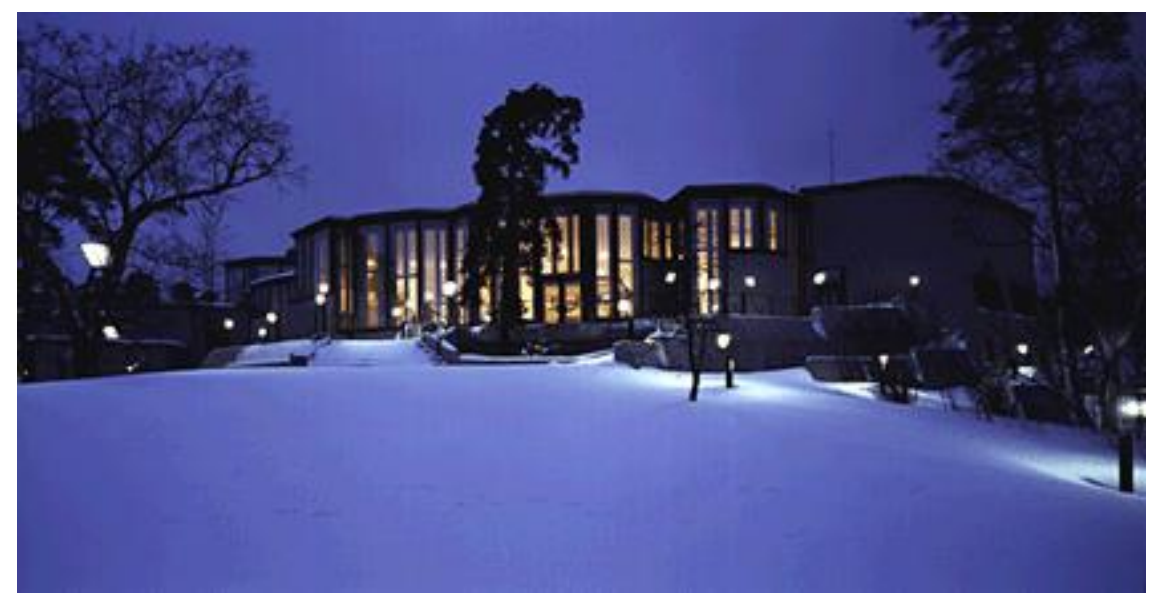

Fig. 7. Night view of Mica Moraine in winter showing the President's residence Mäntyniemi and the building it its natural environs (Photo: Voitto Niemelä 1995).

In Finnish discourse things are put in their place by shameful accusation of 'individualism'. 'Heroism', 'individualism' and 'personal indulgence' are all things which are constantly resented without actually analysing what exactly in the works is questionable or distinguishable. Undeniable achievements are promptly contextualised as exceptions. Timo Tuomi
(2000) notes that even though the architectural establishment had to publish the works of Reima Pietilä, the published project could had been accompanied with a parallel article, which put their architecture in relation with the standard Finnish architecture, and targeted especially heroism. In the case analysed by Tuomi, it was Dipoli: 
It is typical of the ideological crosscurrents of the time that in the same issue of Arkkitehti magazine, 9/1967, in which Dipoli was published and the Pietiläs wrote lyrically about their solution to the brief, the editorial assured that the heroic period of architecture was over. ${ }^{27}$

The past "heroic period" of the 50's was not to be repeated in the 60's which is the Dipoli decade.
Already then Pietilä realised he audits a new version of modernism. In Dipoli, Pietilä tried out the first time genius-loci architecture as response to the individual atmosphere of the location. He noticed the tendency to label his architecture as exception: The "technoculture, which shuns nature-architecture, has regarded Suvikumpu [housing area] and Dipoli as undesirable exceptions [...]." (Pietilä 1985, 14, 15)

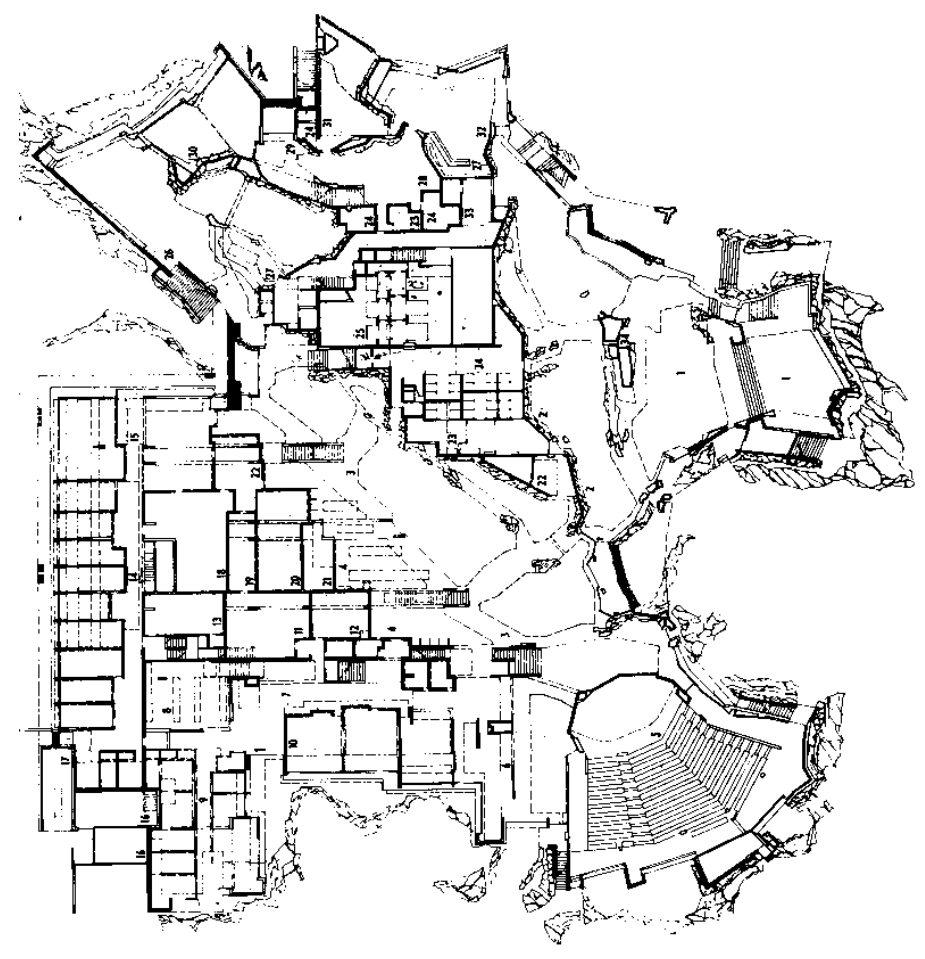

Fig. 8. Dipoli, plan.

The Mica Moraine was treated in an exactly similar manner. Architect Georg Grotenfelt presented his latest designs using timber in Puи (Wood Magazine), $2, \mathbf{1 9 9 3}$, the same issue in which "Mäntyniemi" was published. Mäntyniemi is characterised in the main article as organic; it follows the shapes of the terrain and seems to blend into them. Grotenfelt repeats Salokorpi's and Eskola's claims about the mystic primitivism, while not mentioning the Pietiläs in his article- it is so obvious in Finnish context what he actually means. He states that the best way to follow the organic tradition is to rely on a sound dialogue with the tradition, which sounds like a solid argument. ${ }^{28}$ But the continuation of the article confronted the threat of imitated forms of nature by pointing out what the norm was:

Architecture that respects man and nature is more than [...] a return to more primitive and organic ways of building. Rather, it is a constructive dialogue between man and nature that is based on common sense and cultural traditions. Nature is a great teacher and an object of worship, but all man-made creations should avoid imitation and cheap mystification [emphasis added].

All the accusations made already by Eskola in 1984 are repeated in 1993, e.g. mysticism, organic, commercialism primitivism, imitation of natural forms. In this regard Eskola is correct- Mica Moraine and Dipoli are interrelated, but not via cheap commercialism, rather they have same theoretical background, they are versions of same method, and they were perceived in their time similarly threatening by consensual architects. The rebellious "irrational" architecture reoccurs regardless of the suppression.

2.6 Primitivism as randomness of backwoods' settlements. What is interesting is that the reoccurrence is not any more in the shape of smaller decorative motifs of plants or animals, but something altogether different. The overall composition is free and this is the most fundamental characteristic of site- 
specific solutions of Pietilä, Aalto or indeed Leiviskä. Is the site-specific contingency recognised in the Finnish discourse?

Fortunately there are more clues in Salokorpi's text. Salokorpi argues that in Aalto's architecture one can see "archaic randomness" and contrasts this with the architecture of Mies van der Rohe, in which the free and open-ended (Modern 'progressive') shape of construction is present. Here 'archaic' represents a milder version of 'primitivism'. ${ }^{29}$

This 'archaic' randomness is studied by Sarah Menin (2001) in relation to Aalto's architecture, partly in terms of its relation to the "materiality aspect of the forest" or in the adaption of the Karelian house's ordering totality under which all disparate elements are kept. (Menin, 285-286) An idealised additive, Karelian house unifies the later expansions under the same roof. Menin describes this as a theme of "the lessened control,"(Menin, 290) which refers also to the most cherished compositional ideal of a specific backwoods croft, so called Niemelä torppa compound. This exemplary agglomerative vernacular sample is relocated in the outdoor museum island of Seurasaari, Helsinki. Menin connects the "lessened order" to a metaphor of the deprived Finnishness by Eero Tarasti, "socio-cultural lack" borne out of earlier poor living conditions. ${ }^{30}$

This original lack in 'randomly' scattered units is, I argue, also a lack of refinement, straight lines and other signs of industrialisation. There is nothing heroic about this genesis. It gets, in the argument of this paper, its redemption in the myth of the origin and final outcome of Finnish Modernism: its abandonment of vernacular flexible, non-rational model of the vernacular site-adaptation. In this tradition small differences in terrain and the quality of the openings dictate the spatial organisation. My proposition is to sketch a slightly different genesis of the "other" Finnish Modernism from, "the vernacular backwoods' architecture" (Menin, 282) fertilised by the free form of the National-Romantic Style and strengthened by the demand of rational structure using steel, concrete and glass, purified by the classicism of the 20s. It is eclectic, flexible and culturally orientated.

Randomness is then, following Menin's interpretation, specifically the flexible ideal of the old forest settlements. These solutions always precede the Modern style, even if they survive in vivid figures in the architecture of Aalto and the Pietilä's.

\section{Spatial continuum}

But when the random solution occurs, I argue, either in Aalto's organic compositions or in Juha Leiviskä's scattered larger compositions, ${ }^{31}$ they refer to the kinaesthetic and topological rather than formal premises. This is a living tradition, seamlessly or intuitively picked up by the most site-sensitive of Finnish architects. Salokorpi misses seeing the strength of this genius loci tradition. Pietilä's Mica Moraine is a genuine example of this Finnish sensitiveness towards the site-specific solutions, even if the solution itself is more object-like than a porous weaving of outdoor and indoor spaces of Aalto or Leiviskä. For instance, in the case of Leiviskä, he is actively shaping the spatial continuum looking for a temporal and singular view of architecture. He defines the root space as an "intermediate space", baroque space linking both the interior and exterior, but also a space you are "coming from and space [you are] going to". His topological interconnectedness means that Leiviskä experiences "architecture more by moving within it than by settling down [...].",32

This aspect opens a new perspective to the solutions used by Aalto or Reima Pietilä. Their formal qualities are not upfront, rather the experiential ones. Their architecture draws us into a more or less immediate engagement with the spaces within, which are so well described by Arnold Berleant as environmental engagement. ${ }^{33}$ I can think of one fitting concept, which might explain this - it is Einfühlung or empathy. ${ }^{34}$ It refers to the possibility to enter into the sphere of the object, by forgetting oneself in the immersion and enables one to feel or sense rather than know the qualities of the object in its context - it is both a haptic and optic notion. According to Juliet Koss, it is "an embodied response to an image, object or spatial environment." 35 Temporality of the spatial experience immerses subject to the object. The effect of architecture, when calling for this event, is recognised in the intensive linkage between architecture and the bodily sensations. Architecture affects its perceiver. For Reima Pietilä the task was, "to dissolve [function] within the experiential spatial framework," via perception. (Quantrill, 133) The core atmosphere is gradually, via the process of reassembling and assembling, appearing in drawings which capture synaesthesia of the design. (Pietilä $1985,25)$ 


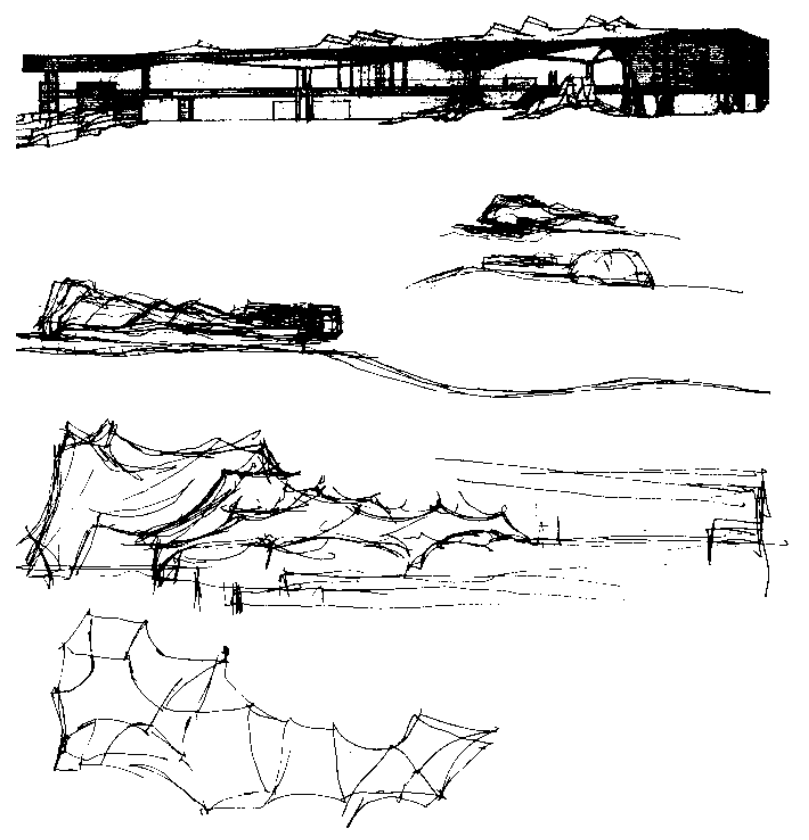

Fig. 9-13. Dipoli developmental sketches.

3.1 The ever-changing interior. In the Mica Moraine we see how Finnish organic architecture evinces spatial continuum as the most important quality of the plasticity. It emphasises the fusion of planes and ambiguity of their position instead of the clarity of planes and the exactitude of their position. How do we perceive the Pietilä's spaces when they become a built reality in Mäntyniemi? For me, Mäntyniemi evokes a magical undulating sphere, which then opens up, while the plastic interiors slowly evolve or linger rhythmically, opening constantly new views as you react to the pressure of the walls. This is exactly how I remembered Reima Pietilä explaining his design decisions while drawing them. His method came as a surprise to me - it was based on an externalised embodied knowledge.

But the result is more than ecstatic immersion. Mäntyniemi is decidedly three-dimensional; that is, one must be aware of the changing views and shifting angles of the walls and ceilings of carved nature. This call for engagement was realised by Pauline von Bonsdorff in her early article about Mica Moraine. ${ }^{36}$ The spaces also evoke other sensual responses: they 'smell', taste and feel, and sometimes they evoke uncanny feelings. We engage with this type of environment with immediacy and potency, because of the distortion of the walls and the fusion of the planes into one continuous container. The spaces are unconventional, and not particularly familiar or cosy.

How is the ambiguity of construction or more precisely, the unsettled existence of planes designed? If within the terms of Einfühlung, the experience is that of immersion, yet the unsettling overall quality of Mica Moraine opposes the permissive connotation of Einfühlung. Einfühlung in its original use had a potentially destabilising connotation. Mica Moraine comprises several unsettling solutions.

3.2 Deviation from the standard of wall. In many instances, the indifference to conventions of the rational architecture of Pietilä's oeuvre can be linked to his obvious inquisitive take on the standard wall-toroof relationship. This is firstly seen in the clear cessation of the ascent of exterior walls in Mica Moraine. Parallel examples are the Pietilä's Malminkartano Experimental Housing (1977-84) and the Kaleva Church.

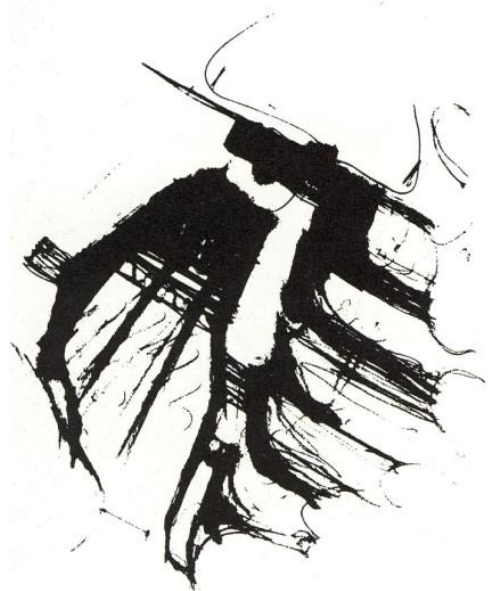

Fig. 14. Sketch of Kaleva Church. 

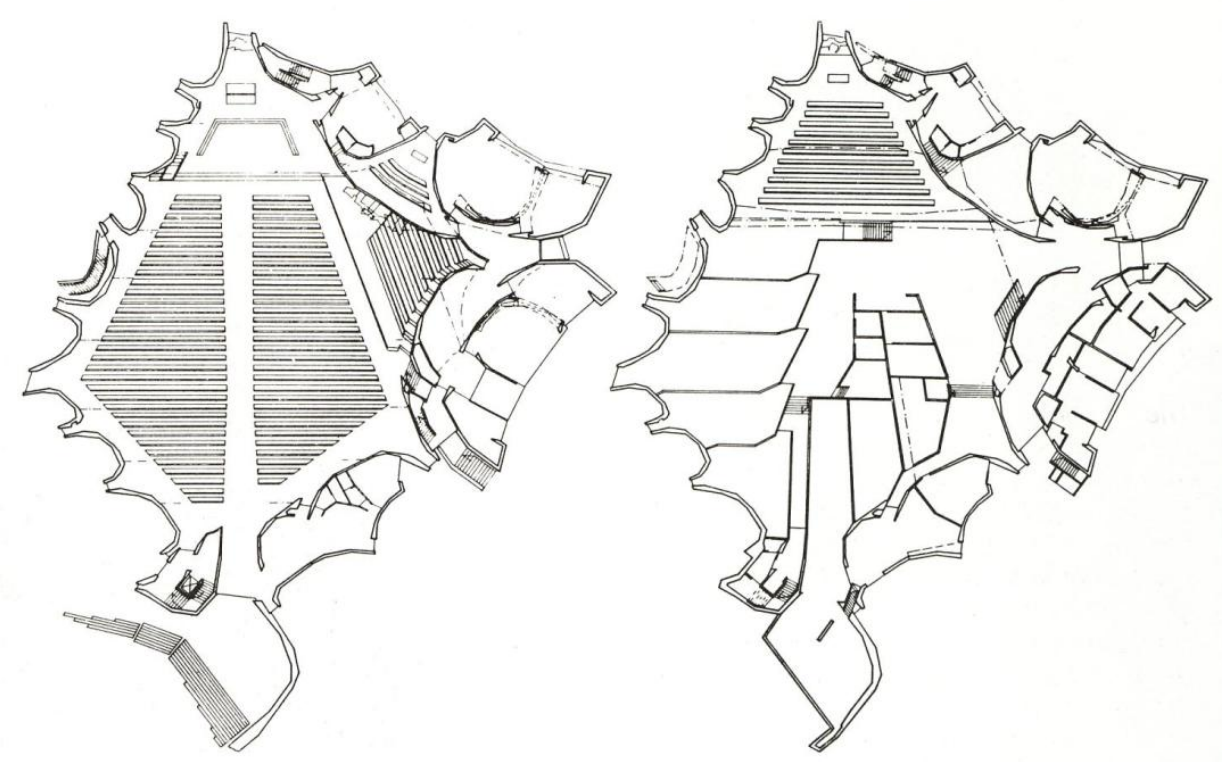

Fig. 15 and 16. Plans of Kaleva Church.
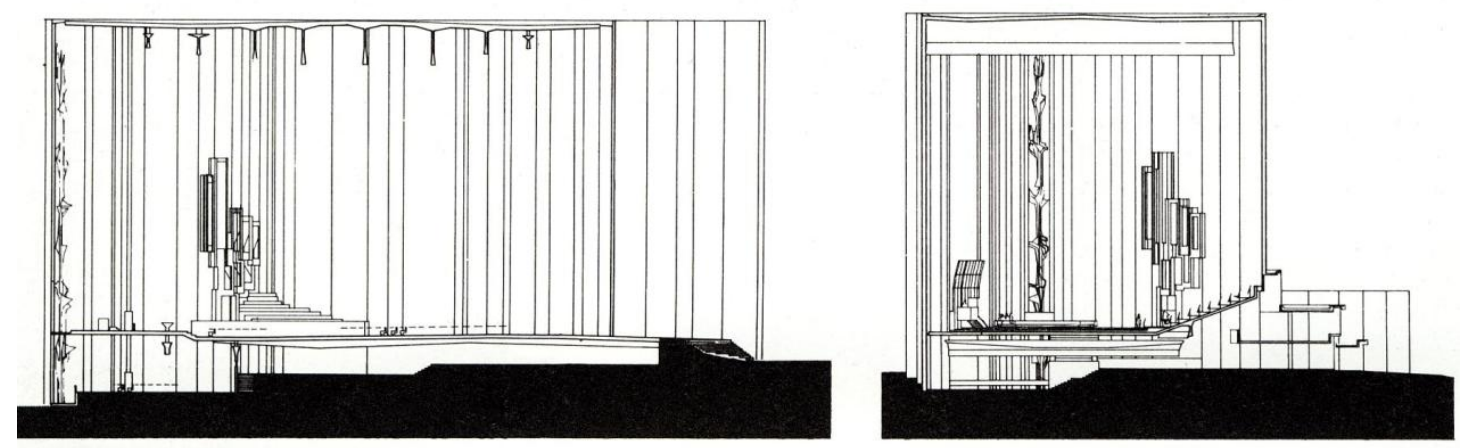

Fig. 17 and 18. Sections of Kaleva Church.

The cessation seems to be arbitrary; there seems to be no compositional or proportional reasons behind the final height of the wall. In the case of Kaleva Church, the pisé wall could have been higher - and was intended to be - and consequently, the volume of the church could have been even more vertical.

However, Pietilä agreed on finishing the casting of the wall earlier thus giving the economical argument the main role in the construction. Also in New Delhi Finnish Embassy $(1963,1980-85)$ the dominating roof structure subordinates other building parts. The wall is dismissed in favour of the roof and ceiling landscapes.
In Mäntyniemi the ceiling is kept potent, hence the exterior looks unbalanced and abruptly cut. Malcolm Quantrill explains Pietilä's ceiling design as a human orientation map with qualitative dimension, which walls alone, if uplifted simply from the plan, couldn't colour (Quantrill, 132). Reima Pietilä deliberately prefers interior over exterior. When exterior acts as a significant sign (referring to glaciers, geological formations and forests), Reima Pietilä refuses to reconcile it with the roof. The gesture of the wall as a carrier of meaning is enough, thus supplementing the dominion of the ceiling. The eve optimises light conditions, but the final solution is far from an ideal accuracy of a minimal Modern solution. 

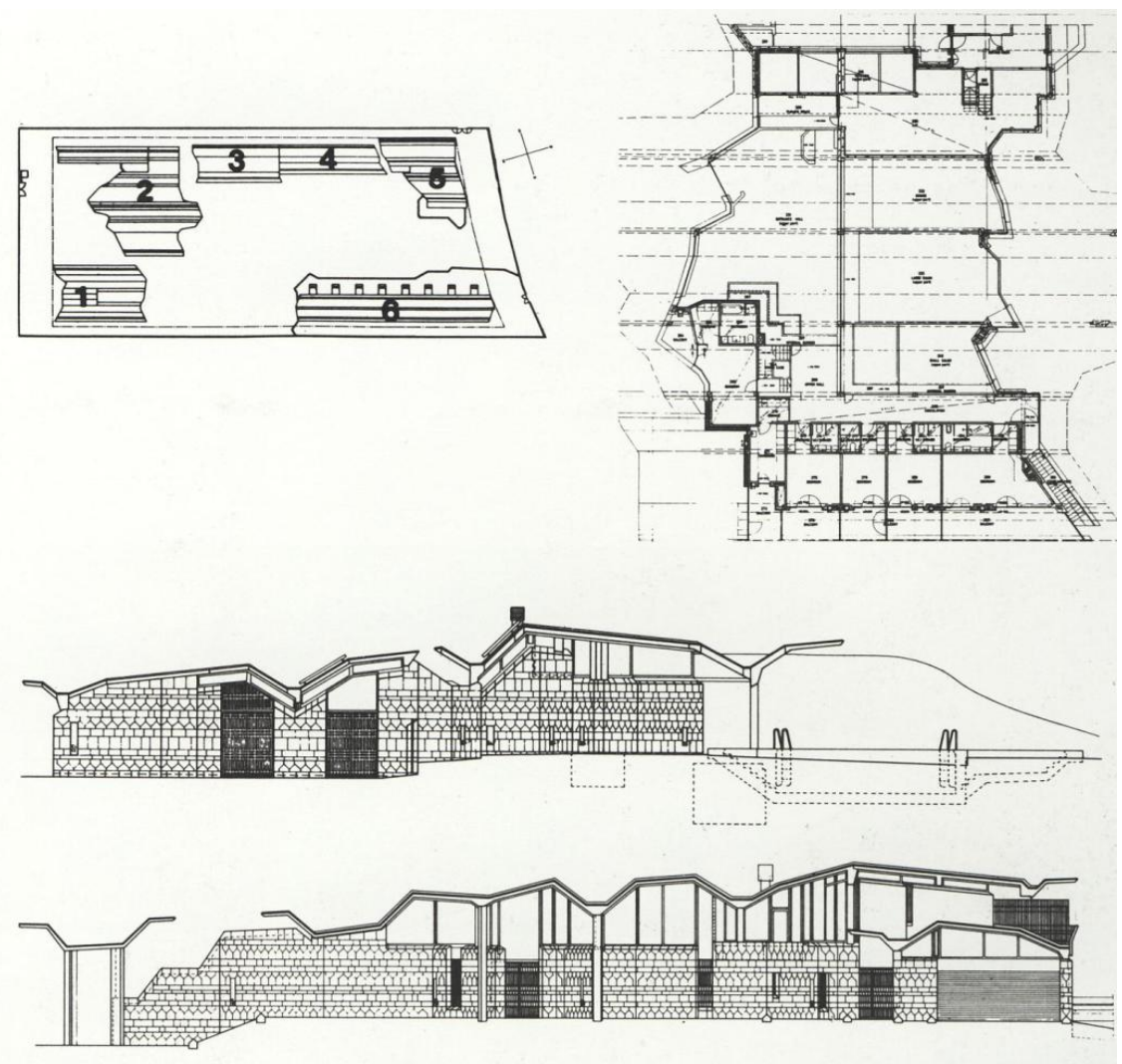

Fig. 19-22. Site-plan, plan and sections of the New Delhi Embassy.
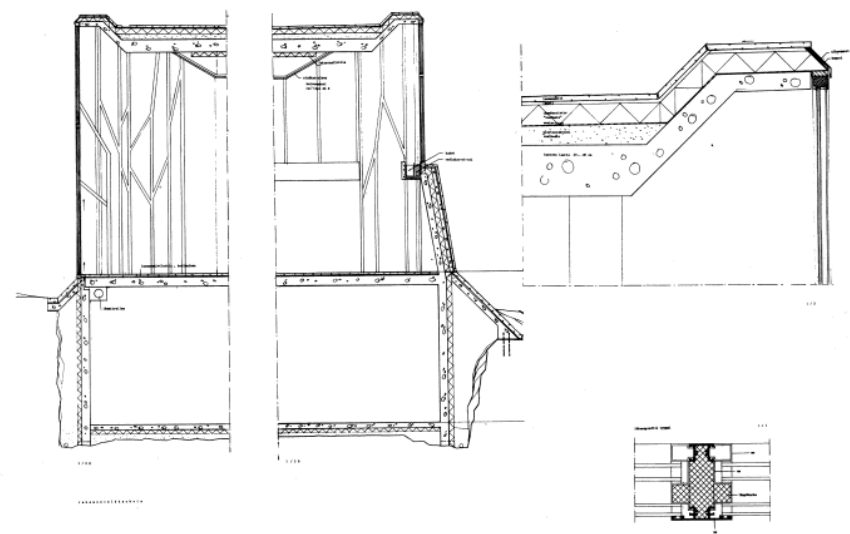

Fig. 23-25. Final wall-joint articulation of Mica Moraine. (Raili Pietilä archive)

The detail drawing and early sketches show how the narrative works [Look at Fig 26-27]. If we look at the early sketches, the viewer is located inside projecting the cone of gaze via the Claude Glass of the glazed wall. Exterior and interior, floor and ceiling are distinguished from each other by the 'swollen' widened - middle part of the window - 'widened for the viewer' [Look at Fig 27]. The perceiver is led to the natural surroundings from inside out via a crystal.
Raili and Reima Pietilä state that the experiential character of the interior and the nature-driven metaphors of the exterior were in focus when designing the Mica Moraine, making sure the "natural metaphors" affect the user:

The early plan sketches for the residence purposely lack hard-structured exteriors, in order that we could study the design as a complete interior phenomenon without a restricting the outer shell of walls. In its 
final form, this outer wall shell became ponderously massive at its base but delicately light at the upper glass areas. - These sketches enable us to develop interior and exterior themes simultaneously. - This building is always "distanced" - kept among natural things - and related to landforms and trees as simultaneous environmental parameters. ${ }^{37}$
One peaceful section per room or corridor would not reveal much. The cave or womb-like spaces create unexpected varied experiences. The interior and exterior are not anymore in a mundane relationship, but rather each of them carry more significance than usual. The space becomes oversaturated with material gestures and tectonic rhetoric.

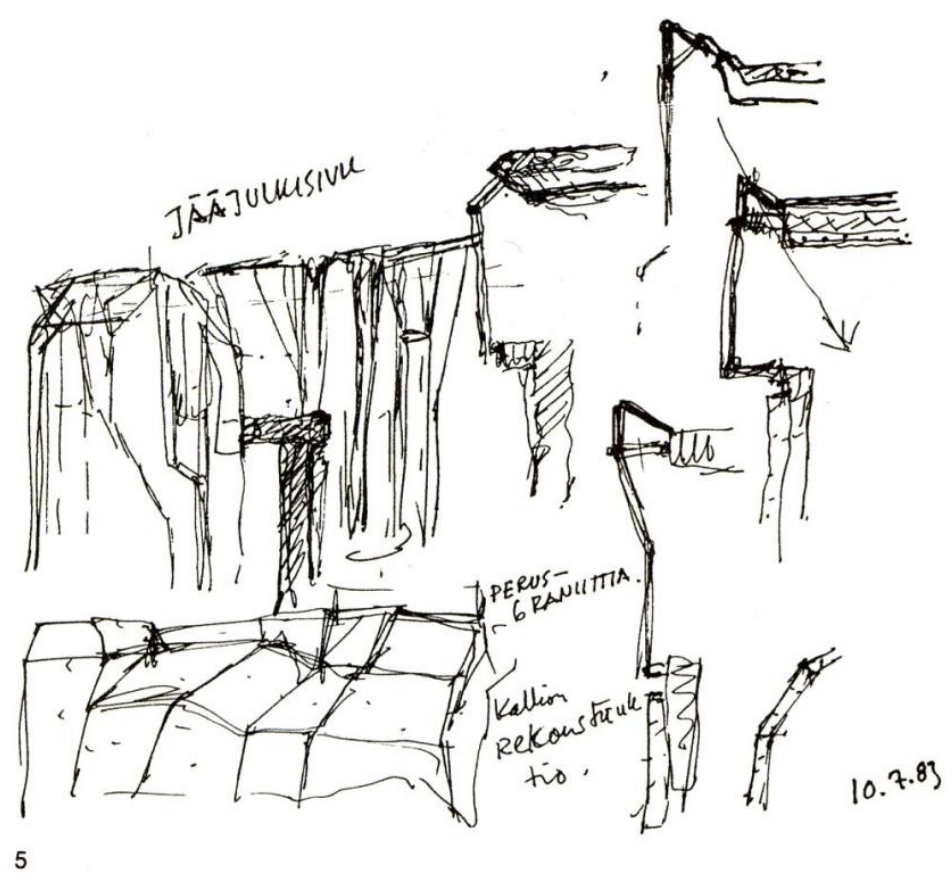

Fig. 26. Reima Pietilä's ideas for the wall-ceiling joint articulation of Mica Moraine. The "basic granite" as a "construction of bedrock" encounters the "ice-facade". Translation of the text in the sketch.

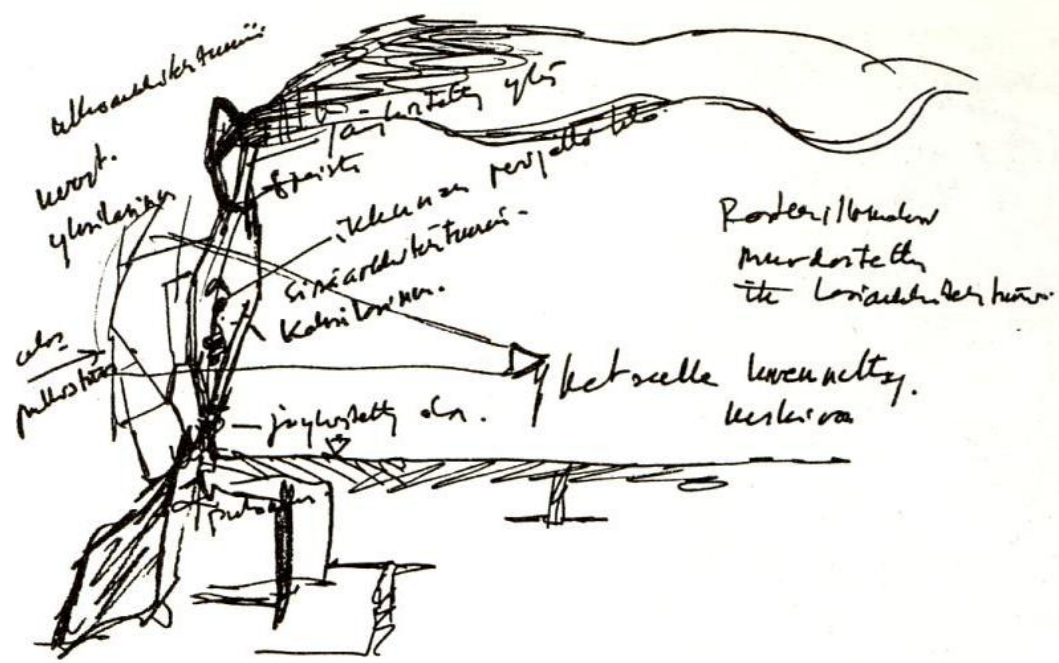

Fig. 27. Reima Pietilä's ideas for the wall-ceiling joint articulation of Mica Moraine. The difference between the exterior and interior is intensified by the acceptance of the viewer, to whom the middle part of the raster of the windows is widen, even suggested diverted vertical. 


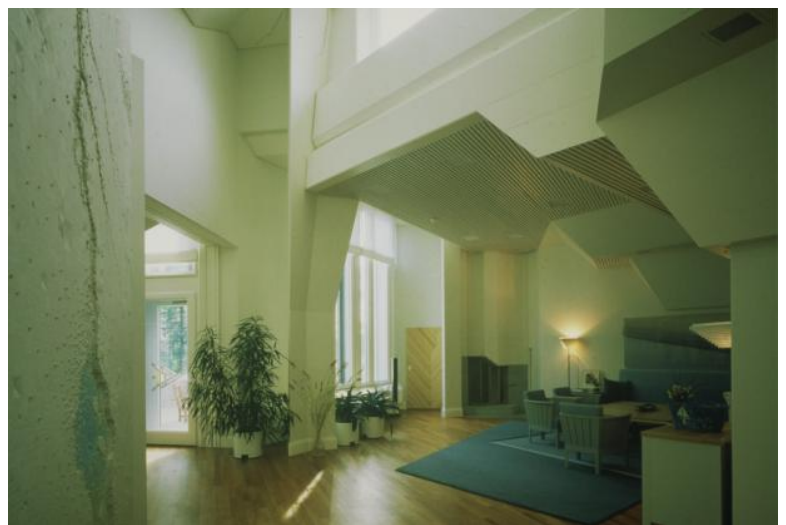

Fig. 28. Lounge of Mäntyniemi (Photo: Voitto Niemelä 1995. Raili Pietilä archive).

3.3 Proliferating space. According to van de Ven, one of the main characteristics of Expressionism is that it loads space with meanings and bodily provocations, so that the experienced space - place becomes a source of accumulated spatial sensations and excessive impressions. In these environments, we are prone to orientate haptically through the space, engage with it, to the point that we become extremely proliferated, drunken with it. ${ }^{38}$ To enlighten this observation, one can turn to the appraisal of a similar ecstasy from the classical text of Pseudo-Longinus. He associated the sublime with an excess of figures in writing. Gruben translates the Latin of Longinus by using the phrase 'word-frenzy' in describing the foamy, repetitive and unnecessarily exaggerated language of Plato. ${ }^{39}$ This is close to the spatial expression of the Pietiläs'; the excessive handling of all the spatial techniques of building. We are not harmoniously immersed with these profligate spaces; rather we are conscious of the oddity of the interior of incremental variations.

Repulsion and attraction defines the nature of the ambiguity of the sublime, which defines the uncanny as well. ${ }^{40}$ Sigmund Freud's presentation of the uncanny consists of, amongst other things, disgusting grottoes or vaginal shapes, as well as the blinding reflection of a mirror or transparency. ${ }^{41}$ If the Pietilä's work represents the sublime of the organic, formless and flesh, we should be able to find the other pole of the sublime, mainly the reduction represented by antiflesh of the surface architecture of hyper-modern rationality. This immateriality triggers another type of paralysing ecstasy.

In environments of visual dominance we may lose our capacity to observe with all our senses; the reflections and lucid glass screens inhibiting our ability to fully engage with the environment. We might be drawn into a fictional sphere, where our inner mental chaos dominates, and we lose touch with the haptic experiential world. The seductive power of the glassy sirens - the new hyper-modern screen architectures - is based on the involvement of our virtual reality. ${ }^{42}$ Two-dimensionality promotes a special type of alienation and detachment.

3.4 Abstract two-dimensional space. Samuli Miettinen wrote a critique of the new university building at the University of Art and Design. The media centre Lume (Virtual) (2000) by architects Heikkinen \& Komonen. ${ }^{43}$ emphasises its twodimensional design principle. He argues that the power of Lume is due to, "the qualities of planes, and especially to the ways they simply confront each other in an indifferent manner. The main tools of this type of architecture are a matter and light, not shape or action." Miettinen continues by describing the materials used, and the co-ordinates created by the juxtapositions of planes:

The systems created by the mathematical divisions cover the surfaces of the workshops weightlessly.

$\mathrm{He}$ is against the excess of the elevations (the letters in the facade annoy him), and accordingly:

Ultimately, a type of architecture, which is using precise repetition and only slight transformations is at its best in extreme conditions. Only then the true qualities of materials are fully utilised using calming large planes.... This design is sufficiently well done; better results could have been possible by reducing the number of tools. As a whole, Lume is a purifying experience, which mends the soul.

The talk is about emotions, acceptable and positive emotions; one can sense the relief, due to aesthetic and visual distance.

Miettinen emphasises the visual perception of the space, which in this case appears to be a simple combination of straight planes with reflective textures of materials and a highly ordered structure. The surfaces dominate the perception; the delight is reached through the matter, or rather through the antimateriality of two-dimensional elements. The pleasure is a kind of a relief in avoiding the overwhelming spatiality. Miettinen certainly mentions the word space in his article, but making sure that we understand that he actually means the surfaces:

The overall impression of the hall is shooting, the surfaces are smooth and beautiful.

Or:

The used materials are juxtapositioned successfully, new surfaces are weightless and light as a dream. The auditorium with its coloured windows is exceptionally brilliant.

Here the visual distance and dazzling effect create the positive sublime in him. We enter the sphere of ideas, where our close senses - smell, touch and taste 
- do not have to function. The orientation mode is on - we use our remote senses - sight and auditive sense. This 'arithmetic' approach diminishes allusions to space in the planes, causing increase of the abstraction of the total space. This is exactly what the Expressionist ideology of Wilhelm Worringer promoted when he opposed Einfühlung. ${ }^{44}$

We can distinguish between two kinds of emotions: the emotion caused by the organic, the one that is too close, the three-dimensional, and the emotion caused by the visually dominated, the one that is too far or rather far enough, the two dimensional. The emotiveintuitive, and rational-logical are two different worlds; thus Pietilä's "methods differ from that of rationalistic modernism, as algebra differs from arithmetic."(Pietilä 1985, 20). The emotional impact of the former one can be ignored because it is too fleshy and material. On the other hand, the emotional impact of the latter helps us to escape this very same materiality. The rationalist view is borne from the assumption that space without residue is present in orthographic projections, and cannot comprehend that space is borne in perception and movement. As Miettinen stated earlier, this architecture is about "matter and light, not shape and action"; for Pietilä it is all these in an unexpected formula, where the contexts and perception rules. Reima Pietilä states about Dipoli, "the aim is no longer that one should see and remember a morphological event just by looking., $" 45$

\section{Conclusion}

The fusion of the body into to space of the Mica Moraine is different from the distanced delight we acquire from the minimal rectangular rationalistic spaces of Heikkinen- Komonen. The Mica Moraine requires acceptance of this radical repositioning of the perceiver into the architectural realm, as Reima Pietilä suggested in his formation of the crystal of glass façade - subjective experience in its fleshiness is a parallax offered by the Pietilä's Mica Moraine. The Pietilä's oeuvre is radical by declaiming new territory between abstraction and matter, in the lived-in space which evaporates from the early crafted drawings. Rational Finnish discourse is not able to appreciate the Pietilä's incorporation of functional, natural and cultural aspects as experienced in the presence of particularities. Rationalism favours conventional representations and universalism. Furthermore this discourse of binary oppositions untenably likens the disparate stylistic motifs of organic, Expressionistic and Romantic origin. Plastic forms of the Pietilä's originate not from stylistic premises but rather from metaphorical and kinaesthetic orders. These are attached to organic Finnish tradition of fusion with the site. If anything, it is interpreting a genius loci.
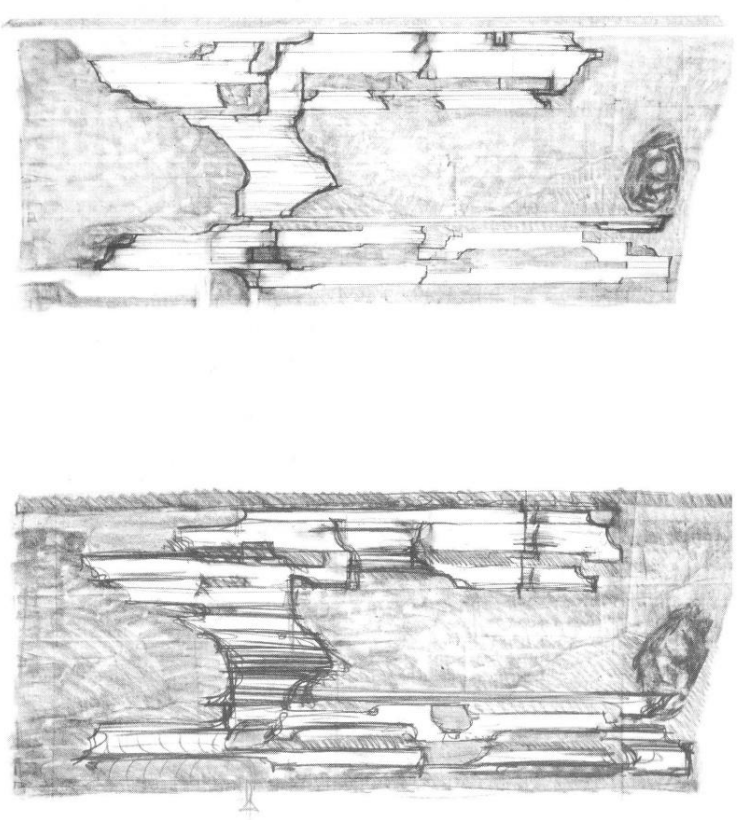

Fig. 29 and 30. New Delhi sketches by Reima Pietilä.

\section{Acknowledgement}

I am grateful to professors Mark Dorrian and Adam Sharr and Dr Hentie Louw at Newcastle University, UK who have discussed this paper with me. Also encouragement from Dr Andy Law was most welcome. Professor Aino Niskanen and Dr Timo Tuomi from Finland were early supporters when this article was originally published in its shorter form. I couldn't have better guide in the archives of the office than Raili Pietilä.

\section{Notes and references}

${ }^{1}$ Aalto, see for instance Pallasmaa, J., 'Alvar Aalto: Toward a Synthetic Functionalism', Alvar Aalto: Between Humanism and Materialism, ed. by Reed, P., New York, The Museum of Modern Art, 1998, 20-45. More specifically Sarah Menin has concentrated on Aalto's relation to forest as he "dismissed Modernist methods." Menin, S., 'Fragments from the forest: Aalto's requisitioning of forest place and matter', The Journal of Architecture, Vol 6, Autumn 2001, 279-305, 280, 287. For Leiviskä, see Blom, K., 'Lainehtiva valo. Undulating light', Ark- Arkkitehti -lehti. Finsk arkitekturtidskrift. The Finnish Architectural Review, 2004, 3, 72-85.

${ }^{2}$ For the Anglo-Saxon perception, look for instance at Jencks, C., Modern Movements in Architecture, London, Penguin Group, 1985, or Reed, P., 'Alvar Aalto and the new Humanism of the Postwar Era', 
Alvar Aalto: Between Humanism and Materialism, New York: The Museum of Modern Art, 1998, 95115, or Treib, M., 'Aalto's nature', in Alvar Aalto: Between Humanism and Materialism, New York: The Museum of Modern Art, 1998, 47-67, or Menin 2001. - Jencks uses the term multivalent for architecture of contradictions and depth as oppose to univalence in formalism. Jencks starts by Aalto's own description of the humane approach to the Modern problem, and sees his architecture as an alternative to the univalent Modern approach. Jencks 1985, 167-183. Best would be Colin St John Wilson: The Other Tradition of Modern Architecture: The Uncompleted Project. London: Academy Editions, 1995.

${ }^{3}$ Caferin, P., 'Suomalaisuutta etsimässä. Suomalainen arkkitehtuuri ulkomaisen lehdistön silmin 1957-67.'

/ 'In pursuit of Finnishness. The foreign press on Finnish architecture, 1957-67', Ark-Arkkitehti lehti. Finsk arkitekturtidskrift. The Finnish Architectural Review 1, 2004, 12-23.

${ }^{4}$ Mica is a group of silicate minerals composed of varying amounts of aluminium, potassium, magnesium, iron and water. All micas form flat, plate-like crystals. Crystals cleave into smooth flakes. Moraine is a mass of material that has been transported by a glacier and then deposited.

5 Arkkitehtiuutiset 9, 1984, 15. The meeting was titled, "The presentation of the design competition for the Official Residence of the President of Finland". The debate was preceded by statements from Arimo Reaeste, competition jury member Juha Leiviskä and Reima Pietilä.

${ }^{6}$ Norri, M-R., Connah, R., Kuosma, K. and Artto, A., eds., Pietilä, Intermediate Zones in Modern Architecture, Helsinki, Museum of Finnish Architecture, 1985, 134.

${ }^{7}$ Pietilä 1985, 129.

8 Eskola, P., 'Keisarin uudet virka-asunnot [The emperor's new official residences]', Arkkitehtiuutiset AU 10, 1984, 20.

${ }^{9}$ Established 1958 by the Finnish group of CIAM.

${ }^{10}$ Quantrill, M., 'The Other Side of the Moon, or Design Theory in the Context of Nature, Culture, and Function', Journal of Architectural Education, Vol. 51, No. 2, November 1997, 127-135, 134.

${ }^{11}$ Pietilä, R. and Price, M., 'Diálogo. Dialogue', De la cultura contemporánea, 2, 1995, 62-95, 70-75. Original Pietilä, R. and Price, M., Miten luonto muovaa / How Nature Forms, Helsinki, Museum of Finnish Architecture, 1983.

12 Colquhoun, A., Modern Architecture, Oxford, Oxford University Press, 2002, 205.
13 Pallasmaa, J., 'Finnish architecture after the Paris Spring', Arkitektur 10, 1986, F10-F16, F2.

${ }^{14}$ Salokorpi, A., Suomen arkkitehtuuria 1900-luvulla, Helsinki, Tammi, 1971, 10.

15 Pallasmaa, since his radical rejection of Expressionism, has condemned the Rational 70s as "pseudo-scientific", Pallasmaa 1986, F2.

${ }^{16}$ Worringer, W., Abstraction and Empathy, trans. by Bullock, M., Chicago, Ivan R. Dee, 1997, 19-21. He refers to Alois Riegl and Theodor Lipps.

17 Salokorpi 1971, 5. See also Gregotti, V., 'Expressionism', Hatje, G., Encyclopaedia of Modern Architecture, New York, Abrams, 1964, 9298, 97.

${ }^{18}$ Gregotti 1964.

19 Braun, E., 'Expressionism as Fascist Aesthetic', Journal of Contemporary History, Vol. 31, 1996, 273-292.

${ }^{20}$ Nerdinger, W., Tafel, C., Architectural Guide Germany $-20^{\text {th }}$ Century, trans. by Taylor, I. and Stern, R., Basel, Berlin, Boston, Birkhäuser, 1996, xi.

${ }^{21}$ Helander, V., in Helander, V., Rista, S., Modern Architecture in Finland, Helsinki, Kirjayhtymä, 1995, 23.

${ }^{22}$ Mukala, J., 'Good building is not an occult science', Arkkitehti/ Finnish Architectural review 2, 2011, 1517, 16.

23 Colquhoun 2002, 205. He refers to Kirmo Mikkola's statements.

24 Dobbins, M., 'The Achievement of Finnish Architecture: Social Responsibility and Architectural Integrity', Perspecta, Vol. 8, 1963, 336, 3-4.

${ }^{25}$ For Pietilä, see Helander 1995, 28, 29; for Aalto especially Ibid., 26. Helander continuously refers to Aalto's individualism, see Ibid., 23-28.

${ }^{26}$ Poole, S., The New Finnish Architecture, New York, Rizzoli, 1992, 35.

${ }^{27}$ Tuomi, T., 'Aspects of the 1960s', eds. Norri, M-R., Standertsjöld, E. and Wang, W., 20 $0^{\text {th }}$ century architecture - Finland, Helsinki, Frankfurt-am-Main, Museum of Finnish Architecture, Deutsches Architektur Museum, 2000, 99-105, 102.

${ }^{28}$ Grotenfelt, G., 'Ihminen, luonto ja arkkitehtuuri', Риu, 2, 1993, 26-39, 30.

${ }^{29}$ Salokorpi 1971, 41-42. Also: “Aalto's architecture [in 50s] was radically new but still archaic and somehow familiar. It is tied to a long European tradition." This observation is interesting: it refers to 
genuine "Finnishness", possibly to vernacular, but also to Italian roots. Helander 1995, 25.

${ }^{30}$ Menin is paraphrasing Eero Tarasti's view on the semiotic silence of Finns, and the concomitant poverty of the Finnish universe of signs. Tarasti, E., 'Finland in the Eyes of a Semiotician', Semiotica, 87-3/4 , 1991, 212. Paraphrased in Menin 2001, 282.

${ }^{31}$ In Aalto, especially the housing in Kauttua (19371946) or Baker House (1947-1948) and Paimio sanatorium (1929-1933) are examples of this; for Leiviskä, for instance his entries to Nokia Headquarters (1983) or Vaasa cemetery competitions (1968).

${ }^{32}$ Leiviskä in Norri, Paatero 1999, 16.

33 Berleant, A., The Aesthetic of Environment, Philadelphia, Temple University Press, 1992.

34 In late $19^{\text {th }}$ century Germany, Einfühlung, or empathy (literally, "feeling into"). This concept comprises ideas from optics, perception psychology, aesthetics, and history. Koss, J., 'On the Limits of Empathy', Art Bulletin, March 2006, Vol LXXVII, number 1, 139-157, 139.

${ }^{35}$ Koss 2006, 139.

36 von Bonsdorff, P., 'Presidential Residence', Form, Function, Finland, 4, 1993, 20-23.

${ }^{37}$ Pietilä, R. and R., 'Oneness of site and nature. How can architecture become contextual with nature? Presidential residence, Mäntyniemi, Helsinki, Fisuras, 2, 1995, 30-35, 33-34.

${ }^{38}$ van de Ven, C., Space in architecture, Maastricht, Corcum Assen, 1987, 156.

39 (Pseudo-) Longinus, On Great Writing (On the Sublime), trans. and ed. Gruben, G. M. A., Indianapolis Cambridge, Hackett Publishing Company, Inc, 1957, 44.

${ }^{40}$ Kearney, R., 'Terror, philosophy and the sublime. Some philosophical reflections on 11 September', Philosophy \& Social Criticism, 2003, Vol 29 no 1, 23-51, 37. He refers to the contrasting nature of the sublime of Kant combining attraction and anxiety.

${ }^{41}$ Freud, S., 'The 'uncanny', eds. Strachey, J. and Freud, A., The standards edition of the Complete Psychological works of Sigmund Freud. Vol. XVI, (Original 'Das Unheimlich', Imago, 5 (5-6), $297-$ 324), The Hogart Press and the Institute of PsychoAnalysis, 1989, 218-256. Reference to "intrauterine" existence, Ibid. 244. Disgust of female genitalia, Ibid., 245. Reference to the unexpected reflection, Ibid., 248. -See also Hélène Cixous, who refers to the endless hesitation of Freud when trying to define what the Uncanny is. The impossibility to define of the notion of the uncanny refers, in her opinion, to the elasticity of the sublime. Cixous, H., 'Fiction and Its Phantoms: A Reading of Freud's 'Das Unheimlich', New Literary History 7, Spring 1976, 252-584, 528.

${ }^{42}$ Blom, K., 'Transparency and Catatonia', ed. Menin, S., Constructing Place: Mind and Matter, New York, Routledge, 2003, 189-201, 196.

${ }^{43}$ Miettinen, S., 'Lumen pinnalla' [On the surface of Lume, Virtual], Ark- Arkkitehti-lehti. Finsk arkitekturtidskrift. The Finnish Architectural Review $3, \mathbf{2 0 0 0}, 46$. Translated by the author. All quotations are from the same page.

${ }^{44}$ Karsten Harris suggested that Worringer's book Abstraction and Empathy "suggested that the situation of modern man demanded an abstract geometric art." Harris, K., The meaning of Modern Art: A Philosophical Interpretation, Evanston, Ill., 1968, 69. This is quoted in Morgan, D., 'Abstraction and Empathy from German Romanticism to Expressionism', Journal of History of Ideas, Vol. 57, No. 2 April 1996, 317-341, 324. Morgan reinforces, "The primary aim of abstraction was to transcend nature by denying space in representation, as Riegl has observed."

${ }^{45}$ Pietilä 1985, 55. 